\title{
WYKAZ PRAC MAGISTERSKICH, DOKTORSKICH I HABILITACYJNYCH ZREALIZOWANYCH W INSTYTUCIE PRAHISTORII UAM W LATACH 2003-2007 (SYGNATURY BIBLIOTEKI INSTYTUTU PRAHISTORII UAM)
}

\section{PRACE MAGISTERSKIE}

1. Alejski Piotr

2007 Macewy poznańskie ze zbiorów muzeum w Żabikowie, 115 k., tabl. (prom. Jerzy Fogel, rec. Hanna Kóčka-Krenz, sygn. 19460)

2. Anders Marcin

2005 Militarne znaczenie Ostrowa Lednickiego w państwie pierwszych Piastów, 89 k., tabl. (prom. Jerzy Fogel, rec. Hanna Kóčka-Krenz, sygn. 19107)

3. Anglart Anna

2003 Części stroju ludności kultury wielbarskiej - faza lubowidzka, (prom. Aleksandra Cofta-Broniewska, rec. Aleksander Kośko)

4. Antończyk Karol

2005 Ryty naskalne $\mathrm{z}$ terenu Szwecji w aspekcie wierzeń społeczeństw w epoce brązu w Skandynawii, 78 k., tabl. (prom. Danuta Minta-Tworzowska, rec. Włodzimierz Rączkowski, sygn. 18994)

5. Apanas Wojciech

2006 Materiały źródłowe kultury łużyckiej ze Środy Wielkopolskiej, woj. wielkopolskie (z dawnych badań amatorskich), 74 k., tabl. (prom. Jerzy Fogel, rec. Hanna Kóčka-Krenz, sygn. 19447)

6. Augustyniak Hubert

2004 Zaopatrzenie w wodę i utrzymanie czystości w Poznaniu, 110 k., tabl. (prom. Hanna Kóčka-Krenz, rec. Jerzy Fogel, sygn. 18779)

7. Bakiewicz Anna

2004 Znaleziska średniowiecznych instrumentów muzycznych z ziem polskich, 146 k., tabl. (prom. Hanna Kóčka-Krenz, rec. Jerzy Fogel, sygn. 18817)

8. Bargielski Radosław

2003 Średniowieczne klucze i kłódki żelazne z terenu Wielkopolski, 100 k., tabl. (prom. Hanna Kóčka-Krenz, rec. Tadeusz Makiewicz, sygn. 18413)

\section{Bartoszewski Tomasz}

2005 Flora i fauna w gospodarce cystersów z Bierzwnika, (prom. Hanna Kóčka-Krenz, rec. Tadeusz Makiewicz)

\section{Beda Justyna}

2007 Średniowieczne znaki pielgrzymie z terenów ziem polskich, 108 k., tabl. (prom. Hanna Kóčka-Krenz, rec. Tadeusz Makiewicz, sygn. 19587) 


\section{Bentkowski Łukasz}

2006 Kwestia megalityzmu w koncepcji tzw. grobowca bezkomorowego w grupie wschodniej i południowo-wschodniej kultury pucharów lejkowatych, (prom. Aleksander Kośko, rec. Janusz Czebreszuk)

\section{Bernaciak Bogna}

2007 Ikonografia „świętych” na kaflach, 93 k., tabl. (prom. Hanna Kóčka-Krenz, rec. Tadeusz Makiewicz, sygn. 19608)

\section{Bigosińska Aleksandra}

2007 Hybrydy zwierzęce w kulturach starożytnej Mezopotamii, 69 k., tabl. (prom. Rafał Koliński, rec. Stefan Zawadzki, sygn. 20336)

14. Bilecki Dominik

2003 Wielowarstwowy cmentarz szkieletowy przy dawnym kościele p.w. Wszystkich Świętych w Poznaniu, 119 k., tabl. (prom. Hanna Kóčka-Krenz, rec. Tadeusz Makiewicz, sygn. 18412)

15. Błaszczyk Honorata

2004 Zastawa stołowa mieszczan poznańskich w średniowieczu, 66 k., tabl. (prom. Hanna Kóčka-Krenz, rec. Dobrochna Jankowska, sygn. 18781)

16. Borkowski Krzysztof

2006 Infrastruktura protomiejska środkowoeuropejskich osad w początkach epoki brązu, 142 k., tabl. (prom. Jerzy Fogel, rec. Hanna Kóčka-Krenz, sygn. 19449)

\section{Bronk Katarzyna}

2003 Sytuacja kulturowa na Półwyspie Jutlandzkim w młodszym okresie przedrzymskim, (prom. Aleksandra Cofta-Broniewska, rec. Aleksander Kośko)

\section{Brzezna Małgorzata}

2004 Osadnictwo neolityczne w Opatowicach, stan. 46, woj. kujawsko-pomorskie, 68 k., tabl. (prom. Aleksander Kośko, rec. Aleksandra Cofta-Broniewska, sygn. 20051)

\section{Buda Bartosz}

2005 Sceny walki na nowoasyryjskich zabytkach z kości słoniowej z Nimrud z pierwszego tysiąclecia przed nasza erą, (prom. Rafał Koliński, rec. Stefan Zawadzki)

\section{Bujak Anna}

2003 Materiały kultury łużyckiej z okolicy Kotowa, pow. Nowy Tomyśl, 67 k., tabl. (prom. Jerzy Fogel, rec. Tadeusz Makiewicz, sygn. 18213)

21. Buraczek Julita

2005 Nekropolia społeczności kultury łużyckiej w Lipiu, pow. Kępno, 118 k., tabl. (prom. Jerzy Fogel, rec. Hanna Kóčka-Krenz, sygn. 19106)

22. Chrapek Magdalena

2005 Przestrzeń kobiety w mieście na przełomie średniowiecza i nowożytności na przykładzie, 234 k., tabl. (prom. Danuta Minta-Tworzowska, rec. Hanna Kóčka-Krenz, sygn. 18998)

\section{Cichocki Wacław}

2003 Relacje przestrzenne między obszarami aktywności osadniczej w schyłkowym paleolicie na stanowisku Żuławka nr 13, 76 k., tabl. (prom. Danuta Minta-Tworzowska, rec. Aleksander Kośko, sygn. 19922)

\section{Ciesielski Tomasz}

2006 Wczesnośredniowieczne przedmioty z poroża i kości ze stanowiska 13b w Gnieźnie, 116 k., tabl. (prom. Hanna Kóčka-Krenz, rec. Jerzy Fogel, sygn. 19264) 


\section{Cieszewska Justyna}

2005 Upadek cywilizacji mykeńskiej. Przegląd obowiązujących hipotez, 192 k., tabl. (prom. Janusz Czebreszuk, rec. Aleksander Kośko, sygn. 19851)

\section{Cytryńska Marta}

2006 Okręgi dolne jako elementy królewskich kompleksów grobowych okresu wczesnodynastycznego, 121 k., tabl. (prom. Rafał Koliński, rec. Michał Kobusiewicz (sygn. 20340)

27. Czekała Romualda

2007 Osadnictwo wczesnośredniowieczne w Czarnkowie na tle osadnictwa w rejonie nadnoteckim, 145 k., tabl. (prom. Hanna Kóčka-Krenz, rec. Jerzy Fogel, sygn. 19582)

\section{8. Ćwiklińska Beata}

2004 Świat człowieka neandertalskiego w perspektywie badań archeologicznych, 84 k., tabl. (prom. Danuta Minta-Tworzowska, rec. Włodzimierz Rączkowski, sygn. 18916)

\section{Dąbal Daria}

2007 Idea rezerwatów archeologicznych. Ochrona i wykorzystanie dziedzictwa archeologicznego, (prom. Danuta Minta-Tworzowska, rec. Aleksander Kośko)

\section{Dąbrowski Bartłomiej}

2007 Uzbrojenie legionów rzymskich podczas podboju Galii przez Juliusza Gajusza Cezara, 110 k., tabl. (prom. Rafał Koliński, rec. Leszek Mrozewicz, sygn. 20335)

31. Dąbrowski Konrad

2007 Pozostałości fortyfikacji poligonalnych Twierdzy Poznań 1828-1869 w świetle nowych danych archeograficznych, 101 k., tabl. (prom. Jerzy Fogel, rec. Zbigniew Pilarczyk, sygn. 19577)

32. Dolata Kamila

2004 Gry planszowe w starożytnym Egipcie, 221 k., tabl. (prom. Dobrochna Jankowska, rec. Rafał Koliński, sygn. 18777)

33. Dotka Dawid

2007 Osadnictwo otwarte we wczesnym średniowieczu w dorzeczu środkowej Obry (VIXI wiek), 122 k., tabl. (prom. Hanna Kóčka-Krenz, rec. Jerzy Fogel, sygn. 19578)

\section{Drejer Agata}

2006 Gospodarka zwierzętami na wczesnobrązowej osadzie w Bruszczewie. Analiza weryfikacyjna materiałów osteologicznych z lat 60. XX wieku, (prom. Janusz Czebreszuk, rec. Daniel Makowiecki)

\section{Dubińska Beata}

2004 Łowiectwo w średniowieczu na terenie Wielkopolski, 108 k., tabl. (prom. Hanna Kóčka-Krenz, rec. Tadeusz Makiewicz, sygn. 19117)

\section{Dulkiewicz Agnieszka}

2006 Szpile kościane i rogowe kultury przeworskiej na terenie Polski, 133 k., tabl. (prom. Tadeusz Makiewicz, rec. Hanna Kóčka-Krenz, sygn. 19440)

\section{Dutkiewicz Jakub}

2005 Zaopatrzenie w wodę klasztoru cysterskiego w Bierzwniku, gm. loco, woj. zachodniopomorskie, 100 k., tabl. (prom. Hanna Kóčka-Krenz, rec. Jerzy Fogel, sygn. 18995) 


\section{Dyczkowski Łukasz}

2007 Nacjonalizm w polskiej archeologii dwudziestolecia międzywojennego jako przejaw władzy w ujęciu Michela Foucaulta na przykładzie badań nad Biskupinem i ich wykorzystania, 64 k., tabl. (prom. Danuta Minta-Tworzowska, rec. Włodzimierz Rączkowski, sygn. 19991)

\section{Dzierżanowska Monika}

2003 Osadnictwo na ziemi szczycieńskiej we wczesnych epokach metali, 46 k., tabl. (prom. Jerzy Fogel, rec. Hanna Kóčka-Krenz, sygn. 18414)

\section{Dziewanowski Marcin}

2004 Świderska koncepcja organizacji przestrzeni konkrecji na przykładzie stanowiska Dręstwo 37, gm. Bargłów Kościelny, (prom. Danuta Minta-Tworzowska, rec. Aleksander Kośko)

\section{Felis Magdalena}

2005 Miniaturowe toporki z X-XIII wieku na ziemiach polskich w kontekście podobnych znalezisk z Europy Północnej i Wschodniej, 99 k., tabl. (prom. Hanna Kóčka-Krenz, rec. Jerzy Fogel, sygn. 19105)

\section{Gajowiecki Pawel}

2003 Wczesnodynastyczne królewskie kompleksy grobowe w Abydos (Egipt). Archeologia krajobrazu, (prom. Danuta Minta-Tworzowska, rec. Lech Krzyżaniak)

\section{Gańska Agnieszka}

2006 Relacje władzy w społeczeństwie polskim w XIII i XIV w. Rola mieczy w ich kształtowaniu, 140 k., tabl. (prom. Danuta Minta-Tworzowska, rec. Włodzimierz Rączkowski, sygn. 19265)

\section{Gil Łukasz}

2005 Fajki gliniane i porcelanowe z Bierzwnika, 107 k., tabl. (prom. Hanna Kóčka-Krenz, rec. Jerzy Fogel, sygn. 18993)

\section{Góra Michał}

2007 Ceramika naczyniowa $\mathrm{z}$ cmentarzyska kultury przeworskiej w Marcjanowie, pow. Turek, stan. 2, 83 k., tabl. (prom. Tadeusz Makiewicz, rec. Hanna Kóčka-Krenz, sygn. 19588)

\section{Góralska Anna}

2007 Ochrona zabytków w Polsce w świetle aktów prawnych i współczesnych zagrożeń, 47 k., tabl. (prom. Danuta Minta-Tworzowska, rec. Włodzimierz Rączkowski, sygn. 19585)

47. Grodzicka Anna

2007 Założenia architektoniczne willi minojskich na Krecie w okresie młodszych pałaców, (prom. Janusz Czebreszuk, rec. Rafał Koliński)

\section{Hauser Piotr}

2005 Zaplecze osadnicze grodu poznańskiego we wczesnym średniowieczu, 110 k., tabl. (prom. Hanna Kóčka-Krenz, rec. Danuta Minta-Tworzowska, sygn. 19109)

\section{Hildebrant Pawe}

2006 Rybołówstwo pradziejowe i wczesnośredniowieczne społeczności biskupińskiego mikroregionu osadniczego, 75 k., tabl. (prom. Jerzy Fogel, rec. Hanna Kóčka-Krenz, sygn. 19452) 


\section{Idziak Magdalena}

2005 Legion XX Valeria Victrix w Brytanii, 78, LXVII k. (prom. Leszek Mrozewicz, rec. Danuta Minta-Tworzowska, sygn. 20346)

51. Ignaszak Krzysztof

2005 Unikatowe formy uzbrojenia z X do XII wieku z obszaru Polski, 122 k., tabl. (prom. Hanna Kóčka-Krenz, rec. Jerzy Fogel, sygn. 19108)

52. Indycka Agnieszka

2006 Osada wczesnośredniowieczna w miejscowości Święty Wojciech, stanowisko 15, gmina Międzyrzecz, powiat międzyrzecki w województwie lubuskim, 146 k., tabl. (prom. Jerzy Fogel, rec. Hanna Kóčka-Krenz, sygn. 19266)

53. Jaeger Mateusz

2006 Osada obronna w Pudliszkach w ramach wczesnobrązowej sieci osadniczej południowej Wielkopolski. Weryfikacje dotychczasowych hipotez, 101 k., tabl. (prom. Janusz Czebreszuk, rec. Aleksander Kośko, sygn. 19383)

\section{Jankowiak Anna}

2003 Ciałopalne cmentarzysko ludności kultury łużyckiej w Dobieszewku, gm. Kcynia, pow. Nakło nad Notecią, 143 k., tabl. (prom. Jerzy Fogel, rec. Hanna Kóčka-Krenz, sygn. 18410)

\section{Jarmuszkiewicz Natalia}

2007 Importy rzymskie w kulturze przeworskiej na Kujawach, 89 k., tabl. (prom.. Aleksandra Cofta-Broniewska, rec. Aleksander Kośko, sygn. 19620)

\section{Jaroni Eliza}

2005 Sztuka naskalna Jebel Uweinat na przykładzie rytów i malowideł z Karkur Talh, (prom. Dobrochna Jankowska, rec. Michał Kobusiewicz)

\section{Jaskulska Anna}

2007 Systematyzacja i interpretacja śladów osadnictwa kultury luboszyckiej na przykładzie osady w Lubieszowie, stan. 1, gm. Wymiarki, woj. lubuskie, 125 k., tabl. (prom. Danuta Minta-Tworzowska, rec. Grzegorz Domański, sygn. 19920)

\section{Kaczmarek Marcin}

2007 Grodziska wczesnośredniowieczne regionu obornickiego, 141 k., tabl. (prom. Tadeusz Makiewicz, rec. Hanna Kóčka-Krenz, sygn. 19805)

\section{Kaniewska Mariola}

2006 Cmentarzysko ludności kultury łużyckiej w Mechlinie, pow. Śrem, 171 k., tabl. (prom. Jerzy Fogel, rec. Hanna Kóčka-Krenz, sygn. 19141)

\section{Karczewska Emilia}

2007 Miejsce plastyki figuralnej w neolitycznych kulturach Mezopotamii, 93 k., tabl. (prom. Rafał Koliński, rec. Dobrochna Jankowska, sygn. 19619)

\section{Karczmarczyk Maricn}

2007 Bartnictwo i jego znaczenie w Polsce we wczesnym średniowieczu, 112 k., tabl. (prom. Jerzy Fogel, rec. Hanna Kóčka-Krenz, sygn. 19680)

62. Kawczak Bartlomiej

2003 Naśladownictwo naczyń szklanych w kulturze przeworskiej w okresie wpływów rzymskich, 145 k. (prom. Tadeusz Makiewicz, rec. Hanna Kóčka-Krenz, sygn. 18367) 


\section{Kępiński Marek}

2007 Przybory tkackie z Ostrowa Tumskiego w Poznaniu, 145 k., tabl. (prom. Hanna Kóčka-Krenz, rec. Danuta Minta-Tworzowska, sygn. 19990)

64. Kiarszys Grzegorz

2004 Społeczne konstruowanie i organizacja przestrzeni we wczesnym średniowieczu na przykładzie mikroregionu Krzywiń, (prom. Danuta Minta-Tworzowska, rec. Włodzimierz Rączkowski)

\section{Kiecko Dorota}

2005 Przedstawienia dionizyjskie na ceramice greckiej (kolekcja Campana z Muzeum w Luwrze), 76 k., tabl., (prom. Leszek Mrozewicz, rec. Danuta Minta-Tworzowska, sygn. 20345)

66. Klaudel Bartłomiej

2005 Średniowieczna zabudowa drewniana kwartału A-20 na Starym Mieście w Głogowie, 122 k., tabl. (prom. Hanna Kóčka-Krenz, rec. Tadeusz Makiewicz, sygn. 19115)

\section{Klimowicz Arkadiusz}

2006 Dynamika wzrostu statusu domów i ich społeczny kontekst na neolitycznym Tellu Ģatalhöyük w środkowej Turcji, (prom. Danuta Minta-Tworzowska, rec. Lech Czerniak)

68. Knop Anna

2005 Przedmioty z kości i poroża górnego paleolitu w Polsce, 98 k., tabl. (prom. Michał Kobusiewicz, rec. Dobrochna Jankowska, sygn. 19802)

\section{Kokolus Justyna}

2003 Elementy kręgu jastorfskiego w kulturze Polenosti-Lukasevka, (prom. Aleksandra Cofta-Broniewska, rec. Aleksander Kośko)

\section{Kołoszuk Igor}

2004 Zmiana kulturowa w paradygmacie kognitywo-procesualnym na przykładzie wczesnołużyckiego cmentarzyska w Kietrzu, stanowisko nr 1, woj. opolskie, 157 k., tabl. (prom. Danuta Minta-Tworzowska, rec. Janusz Czebreszuk, sygn. 20356)

\section{Kowalczuk Agnieszka}

2005 Osadnictwo z okresu wpływów rzymskich na wzgórzu klasztornym w Bierzwniku, woj. zachodniopomorskie, (prom. Aleksandra Cofta-Broniewska, rec. Aleksander Kośko)

72. Kowalczyk Andrzej

2007 Ceramika kamionkowa z Ostrowa Tumskiego w Poznaniu, 178 k., tabl. + płyta CD (prom. Hanna Kóčka-Krenz, rec. Jerzy Fogel, sygn. 19579)

73. Kozłowski Jakub

2003 Socjotopografia Płocka X-XIII wiek, 238 k., tabl. (prom. Danuta Minta-Tworzowska, rec. brak, sygn. 18505)

74. Kranc Małgorzata

2003 Analiza ceramiki z cmentarzyska Gordijewka, Raj. Trostianec, Obw. Winnica (Ukraina). Problem identyfikacji topogenetycznej (prom. Aleksander Kośko, rec. Aleksandra Cofta-Broniewska)

\section{Krueger Michał}

2004 Żegluga fenicka w zachodniej części śródziemnomorza i na Oceanie Atlantyckim, 101 k., tabl. (prom. Rafał Koliński, rec. Leszek Mrozewicz, sygn. 20337) 


\section{Krupińska Marta}

2005 Przedstawienia kobiet w symbolice społeczności wczesnoneolitycznych, (prom. Danuta Minta-Tworzowska, rec. Włodzimierz Rączkowski)

\section{Krybus Natalia}

2006 Znaczenie mamuta (Mammuthus primigenius) dla człowieka we wczesnych pradziejach Europy, 82 k., tabl. (prom. Michał Kobusiewicz, rec. Dobrochna Jankowska, sygn. 19172)

78. Krzynowek-Kulińska Florentyna

2005 Gród wczesnośredniowieczny w Raszewach, gm. Żerków, pow. Jarocin, 84 k., tabl. (prom. Jerzy Fogel, rec. Hanna Kóčka-Krenz, sygn. 19113)

79. Krzyżaniak Bartosz

2006 Mur Hadriana w świetle badań archeologicznych, 133 k., tabl. (prom. Tadeusz Makiewicz, rec. Rafał Koliński, sygn. 19450)

80. Kubaczyk Justyna

2006 Cmentarzysko ludności kultury łużyckiej w Czaczu, gm. Śmigiel, 104 k., tabl. (prom. Jerzy Fogel, rec. Hanna Kóčka-Krenz, sygn. 19238)

\section{Kucharska Marta}

2003 Metalurgia żelaza w klasztorze cysterskim w Bierzwniku, stanowisko 1, woj. zachodniopomorskie od końca XIII do połowy XVI wieku, (prom. Aleksandra Cofta-Broniewska, rec. Aleksander Kośko)

\section{Kufel Mariusz}

2006 Wyspa Thera (Santorium) w epokach neolitu i brązu w świetle badań archeologicznych i interdyscyplinarnych, 51 k. (prom. Janusz Czebreszuk, rec. Aleksander Kośko, sygn. 19251)

83. Kumoś-Lisiecka Agata

2006 Osadnictwo wczesnośredniowieczne w rejonie Obrzycka, 91 k., tabl. (prom. Hanna Kóčka-Krenz, rec. Tadeusz Makiewicz, sygn. 19267)

\section{Kurkowicz Joanna}

2005 Wczesnośredniowieczne techniki budowlane w kamiennej architekturze Wielkopolski i Kujaw od 2 poł. X do 1 poł. XII w., 207 k. (prom. Hanna Kóčka-Krenz, rec. Tadeusz Makiewicz, sygn. 19806)

\section{Kurzawski Piotr}

2005 Architektura południowo-zachodniego Iranu w II połowie IV i na początku III tysiąclecia p.n.e., 217 k., tabl. (prom. Rafał Koliński, rec. Danuta Minta-Tworzowska, sygn. 20339)

\section{Kwiatkowski Karol}

2007 Zoomorficzne figurki Anubisa w ikonografii oraz w praktykach pogrzebowych starożytnych Egipcjan, 251 k., tabl. (prom. Rafał Koliński, rec. Danuta Minta-Tworzowska, sygn. 20334)

\section{Leciejewska Anna}

2003 Osadnictwo wczesnośredniowieczne z okolic Giecza, 56 k., tabl. (prom. Hanna Kóčka-Krenz, rec. Tadeusz Makiewicz, sygn. 18376)

\section{Lipkowska Anna Katarzyna}

2005 Zapinki IV grupy według Oskara Almgrena w Wielkopolsce, 172 k., tabl. (prom. Tadeusz Makiewicz, rec. Hanna Kóčka-Krenz, sygn. 19118) 


\section{Lipowczyk Natalia}

2005 Symbolika władzy w sztuce wczesnochrześcijańskiej, 170, LX k., tabl. (prom. Leszek Mrozewicz, rec. Danuta Minta-Tworzowska, sygn. 20344)

\section{Loba Ewa}

2006 „Import” nordyjski na ziemiach polskich w starszej epoce brązu, 150 k., tabl. (prom. Jerzy Fogel, rec. Hanna Kóčka-Krenz, sygn. 19268)

\section{1. Łączkowski Mariusz}

2006 Życie codzienne w północnej Syrii w świetle monumentalnej sztuki nowohetyckiej, 79 k., tabl. (prom. Rafał Koliński, rec. Stefan Zawadzki, sygn. 20341)

\section{Maciejewski Kamil}

2006 Handel śledziami w dorzeczu Odry we wczesnym średniowieczu w świetle badań archeologicznych i historycznych. Przykład Wolina i Wrocławia w wiekach VIIIXIII, 135 k., tabl. (prom. Danuta Minta-Tworzowska, rec. Hanna Kóčka-Krenz, sygn. 19252)

\section{Maciejewski Marcin}

2005 Przemiany kulturowe społeczności epoki brązu i wczesnej epoki żelaza w rejonie środkowej Noteci, 2 vol., 229 k., tabl., mapy (prom. Aleksander Kośko, rec. Aleksandra Cofta-Broniewska, sygn. 20315)

\section{Maciejewski Rafa1}

2005 Dwie osady ludności kultury łużyckiej z okresu halsztackiego w Wenecji, pow. Żnin (stan. 6 i 7), 78 k., tabl. (prom. Jerzy Fogel, rec. Hanna Kóčka-Krenz, sygn. 19111)

\section{Magiera Izabela}

2003 Obrzędy pogrzebowe Scytów na terenie dolnego Naddnieprza w okresie od początku V w. p.n.e. do IV/III w. p.n.e., 127 k., tabl. (prom. Danuta Minta-Tworzowska, rec. Aleksander Kośko, sygn. 18570)

\section{Majchrzycki Michał}

2006 Bycie Biskupina w dyskursie polskiej archeologii, (prom. Włodzimierz Rączkowski, rec. Danuta Minta-Tworzowska)

97. Majek Katarzyna

2003 Problem pochodzenia tzw. skarbów strzyżowskich, 67 k. (prom. Aleksander Kośko, rec. Aleksandra Cofta-Broniewska, sygn. 20322)

\section{Maluśki Paweł}

2005 Średniowieczna i nowożytna ceramika naczyniowa z Zamku Kórnickiego, 116 k., tabl. (prom. Jerzy Fogel, rec. Hanna Kóčka-Krenz, sygn. 19000)

99. Marciniak Iwona

2004 Wyroby włókiennicze odkryte na stanowisku Ostrów Tumski 9/10 w Poznaniu, 129 k., tabl. (prom. Hanna Kóčka-Krenz, rec. Jerzy Fogel, sygn. 18780)

\section{Matuszewska Agnieszka}

2003 Udział wzorców kulturowych wiązanych z pucharami dzwonowatymi w rozwoju społeczności międzyrzecza Wisły i Dniepru, 58 k., tabl. (prom. Aleksander Kośko, rec. Janusz Czebreszuk, sygn. 20321)

\section{Matuszewska Marta}

2004 Ceramika budowlana z Novae z sezonów 1995-2003, 100 k., tabl. (prom. Tadeusz Makiewicz, rec. Hanna Kóčka-Krenz, sygn. 18659) 
102. Merklinger-Czerwieniec Marta

2004 Monety sasanidzkie na obszarze basenu Morza Bałtyckiego, 171 k., tabl. (prom. Hanna Kóčka-Krenz, rec. Tadeusz Makiewicz, sygn. 18807)

\section{Michalik Julian}

2003 Stan badań nad średniowiecznymi ośrodkami miejskimi na obszarze dzisiejszej Białorusi, 178 k. (prom. Hanna Kóčka-Krenz, rec. Aleksander Kośko, sygn. 18406)

\section{Michalski Marcin}

2007 Prospekcja geomagnetyczna w archeologii. Przykład nieinwazyjnego rozpoznania wybranych osad obronnych z okresu halsztackiego na terenie Pałuk i Wielkopolski, 113 k., tabl. (prom. Danuta Minta-Tworzowska, rec. Włodzimierz Rączkowski, sygn. 19782)

\section{Miciak Magda}

2005 Grodzenie na cmentarzysku w Gieczu, woj. wielkopolskie, na tle podobnych cmentarzysk na ziemiach polskich we wczesnym średniowieczu, 119 k., tabl. (prom. Danuta Minta-Tworzowska, rec. Hanna Kóčka-Krenz, sygn. 19112)

106. Mikuła Ryszard Kazimierz

2004 Ceramika hellenistyczna i rzymska ze stanowiska TP w Cątalhöyük, Turcja: analiza układów przestrzennych w skali mikroosadniczej, 117 k., tabl. (prom. Danuta Minta-Tworzowska, rec. Tadeusz Makiewicz, sygn. 19269)

\section{Moryl Krystian}

2005 Uzbrojenie ludności kultury przeworskiej na Kujawach, (prom. Aleksandra Cofta-Broniewska, rec. Aleksander Kośko)

108. Myrcha Jacek

2003 Ceramika wczesnośredniowieczna z wykopu 2 na Ostrowie Tumskim w Poznaniu (stan. OT 10), 57 k., tabl. (prom. Hanna Kóčka-Krenz, rec. Tadeusz Makiewicz, sygn. 18408)

\section{Niedźwiecki Rafał}

2005 Społeczności okresu przedrzymskiego w dorzeczu środkowej Noteci, (prom. Aleksandra Cofta-Broniewska, rec. Aleksander Kośko)

110. Nowacka Justyna

2003 Napierśnik kultury pomorskiej z Przycimia-Brzęczka, stan. 76/104, pow. Świecie. Nowe znalezisko, 53 k., tabl. (prom. Jerzy Fogel, rec. Hanna Kóčka-Krenz, sygn. 18361)

\section{Nowicka Aleksandra}

2004 Obrządek pogrzebowy w Nubii w epoce kamienia, (prom. Michał Kobusiewicz, rec. Lech Krzyżaniak)

\section{Nowicka Monika}

2006 Wytwarzanie i zastosowanie dziegciu w kulturze łużyckiej. Badania przeprowadzone w oparciu o analizy fizykochemiczne, (prom. Danuta Minta-Tworzowska, rec. Jerzy Langer)

113. Nowicki Jakub

2006 Agrotechnika na ziemiach polskich w dobie kultury łużyckiej, 112 k., tabl. (prom. Jerzy Fogel, rec. Hanna Kóčka-Krenz, sygn. 19448)

\section{Olczak Barbara}

2007 Wierzenia pogańskie a chrystianizacja Irlandii we wczesnym średniowieczu, 104 k., tabl. (prom. Hanna Kóčka-Krenz, rec. Tadeusz Makiewicz, sygn. 19617) 


\section{Olejnik Monika}

2006 Ceramika późnośredniowieczna i nowożytna z Obornik Wielkopolskich, 68 k., tabl. (prom. Hanna Kóčka-Krenz, rec. Tadeusz Makiewicz, sygn. 19441)

\section{Olędzki Łukasz}

2003 Kurhan jak element rytuału ludów koczowniczych. Interpretacja symboliczna kurhanu Arzan w Tuwie, 233 k., tabl. (prom. Danuta Minta-Tworzowska, rec. Aleksander Kośko, sygn. 18573)

\section{Pałczyńska Anna}

2004 Chrześcijańska ceramika naczyniowa ze stanowiska Sirada (Sudan), (prom. Danuta Minta-Tworzowska, rec. Rafał Koliński)

\section{Pałczyński Marcin}

2003 Osadnictwo wczesnośredniowieczne w dolinie rzeki Cybiny wokół jeziora Góra, 78 k. (prom. Hanna Kóčka-Krenz, rec. Tadeusz Makiewicz, sygn. 18568)

\section{Papież Justyna}

2004 Postacie świętych i aniołów na gotyckich kaflach piecowych z Gniezna i jego okolic, 81 k., tabl. (prom. Danuta Minta-Tworzowska, rec. Hanna Kóčka-Krenz, sygn. 18806)

\section{Pieczarka Agnieszka}

2005 Gród z wczesnej epoki żelaza w miejscowości Baldram, woj. pomorskie (stan. 1), 117 k., tabl. (prom. Jerzy Fogel, rec. Hanna Kóčka-Krenz, sygn. 19001)

\section{Pietras Mateusz}

2004 Gotycka ceramika budowlana ze stanowiska Ostrów Tumski 9/10 w Poznaniu, 95 k., tabl. (prom. Hanna Kóčka-Krenz, rec. Tadeusz Makiewicz, sygn. 18981)

\section{Pietrzak Iwona}

2005 Architektura i symbolika ideowo-religijna Panteonu, (prom. Leszek Mrozewicz, rec. Danuta Minta-Tworzowska)

\section{Piłaszewicz Damian}

2006 Zastosowanie metody makroskopowej i eksperymentalnej do badań nad wytwarzaniem neolitycznej ceramiki naczyniowej na przykładzie materiałów z osady w Szczecinie-Ustowie, T. 1 - 275 k., T. 2 - tabl. I tab. (prom. Dobrochna Jankowska, rec. Hanna Kóčka-Krenz, sygn. 19237)

\section{Płaczek Magdalena}

2007 Zmiany ułożenia ciał zmarłych w starożytnym Egipcie od okresu predynastycznego do Nowego Państwa, 127 k., tabl. (prom. Rafał Koliński, rec. Dobrochna Jankowska, sygn. 19804)

\section{Pochylski Mariusz}

2007 Wytwórczość metalurgiczna w okresie przedrzymskim i wpływów rzymskich na Pomorzu, 109 k., tabl. (prom. Tadeusz Makiewicz, rec. Hanna Kóčka-Krenz, sygn. 19584)

\section{Podliński Damian}

2005 Osada ludności kultury przeworskiej na stan.23 B w Sowinkach, pow. poznański, cz. południowa, 60 k., tabl. (prom. Tadeusz Makiewicz, rec. Hanna Kóčka-Krenz, sygn. 18943) 


\section{Podliński Radosław}

2005 Osada ludności kultury przeworskiej na stan. 23 B w Sowinkach, pow. poznański, cz. północna, 58 k. tabl. (prom. Tadeusz Makiewicz, rec. Hanna Kóčka-Krenz, sygn. 18942)

\section{Pospieszny Lukasz}

2007 Groby kultury ceramiki sznurowej w Wielkopolsce i na Kujawach, (prom. Janusz Czebreszuk, rec. Aleksander Kośko)

129. Przybylska Patrycja

2007 Władza a mechanizmy utrwalania porządku na podstawie materiałów kultury scytyjskiej z terenów północnego nadczarnomorza z okresu między V a III w.p.n.e., 77 k., tabl. (prom. Danuta Minta-Tworzowska, rec. Włodzimierz Rączkowski, sygn. 19583)

\section{Przygodzka Joanna}

2005 Czy archeologia naprawdę ratownicza?, 122 k., tabl. (prom. Danuta Minta-Tworzowska, rec. Włodzimierz Rączkowski, sygn. 18997)

\section{Pudliszak Katarzyna}

2007 Osada kultury jastorfskiej w Inowrocławiu 101, woj. kujawsko-pomorskie, (prom. Aleksandra Cofta-Broniewska, rec. Aleksander Kośko)

\section{Pyżewicz Katarzyna}

2003 Analiza funkcjonowania mezolitycznych zbrojników krzemiennych ze stanowiska Żuławka 13, gm. Wyrzysk, pow. Piła, woj. wielkopolskie, (prom. Dobrochna Jankowska, rec. Janusz Czebreszuk, sygn. 20357)

133. Quasner Katarzyna

2004 Wyroby szkliwne z wczesnośredniowiecznych inwentarzy prawobrzeża środkowej Warty, 73 k., tabl. (prom. Jerzy Fogel, rec. Hanna Kóčka-Krenz, sygn. 18690)

\section{Radniecki Przemysław}

2004 Władza we wczesnośredniowiecznej Polsce na przykładzie zespołu architektonicznego z Ostrowa Lednickiego, 147 k., tabl. (prom. Danuta Minta-Tworzowska, rec. Hanna Kóčka-Krenz, sygn. 18778)

\section{Rajewicz Alicja}

2005 Figurka Besa z Muzeum Archeologicznego w Poznaniu, 124 k., tabl. (prom. Dobrochna Jankowska, rec. Rafał Koliński, sygn. 19803)

\section{Rasińska Iwona}

[2004] Obraz archeologii polskiej w Internecie, 84 k., tabl. (prom. Włodzimierz Rączkowski, rec. Danuta Minta-Tworzowska, sygn. 18641)

\section{Rejchert Michał}

2007 Analiza technologiczna i morfologiczna ceramiki ze stanowiska Dąbki 9, gm. Darłowo, pow. Sławno, (prom. Dobrochna Jankowska, rec. Michał Kobusiewicz)

\section{Rek Magdalena}

2004 Kwestia demonologii w kulturze duchowej mieszkańców ziem polskich w okresie średniowiecza, 187 k., tabl. (prom. Hanna Kóčka-Krenz, rec. Tadeusz Makiewicz, sygn. 18676)

\section{Reszel Maciej}

2006 Geneza neolitu w strefie lasostepu międzyrzecza Wołgi i Uralu, 148 k. (prom. Aleksander Kośko, rec. Marzena Szmyt, sygn. 20314) 
140. Rojkowski Dominik

2005 Rola dzikich zwierząt w gospodarce mieszkańców wczesnośredniowiecznej Wielkopolski, 95 k., tabl. (prom. Hanna Kóčka-Krenz, rec. Jerzy Fogel, sygn. 19121)

\section{Roman Adriana}

2004 Rola i pozycja kobiety w starożytnej Mezopotamii, (prom. Rafał Koliński, rec. Danuta Minta-Tworzowska)

142. Rozbicki Paweł

2004 Interpretacja fenomenologiczna paleolitycznej sztuki naskalnej na przykładzie jaskini Lascaux, (prom. Danuta Minta-Tworzowska, rec. Włodzimierz Rączkowski)

143. Rozwadowski Michał

2005 Ceramika z wykopów 93E i 94E, stanowisko w Tell El-Farcha, (prom. Dobrochna Jankowska, rec. Michał Kobusiewicz)

\section{Rudziński Paweł Michał}

2005 Tarcza jako broń ochronna wczesnośredniowiecznych Słowian na tle uzbrojenia europejskiego, 95 k., tabl. (prom. Hanna Kóčka-Krenz, rec. Jerzy Fogel, sygn. 19119)

145. Rutkowska Ewa

2003 Osadnictwo wczesnośredniowieczne na wzgórzu klasztornym w Bierzwniku, woj. zachodniopomorskie, 71 k., tabl. (prom. Hanna Kóčka-Krenz, rec. Dobrochna Jankowska, sygn. 18336)

\section{Sadowska Małgorzata}

2004 Charakterystyka wyposażenia zmarłych na wczesnośredniowiecznych cmentarzyskach Wielkopolski, 138 k., tabl. (prom. Hanna Kóčka-Krenz, rec. Tadeusz Makiewicz, sygn. 18639)

147. Sakrajda Przemysław

2005 Interpretacje wybranych wizerunków postaci ludzkich na rytach naskalnych w regionach Ostfold, Bohuslav, Dalslund, 67 k., tabl. (prom. Danuta Minta-Tworzowska, rec. Włodzimierz Rączkowski, sygn. 18915)

\section{Sankiewicz Pawel}

2006 Wczesnośredniowieczne umocnienia obronne grodu na Ostrowie Tumskim w Poznaniu, 110 k., tabl. (prom. Hanna Kóčka-Krenz, rec. Jerzy Fogel, sygn. 19236)

\section{Sargalis Karolina}

2003 Ceramika siwa na ziemiach polskich od połowy XIII do końca XV wieku. Pochodzenie, charakterystyka, problemy, 66 k., tabl. (prom. Hanna Kóčka-Krenz, rec. Tadeusz Makiewicz, sygn. 18407)

150. Siara Karolina

2007 Zagadnienie nieobecności kostnych szczątków człowieka neandertalskiego na terenie Polski, 114 k., tabl. (prom. Michał Kobusiewicz, rec. Dobrochna Jankowska, sygn. 19586)

151. Sikora Mateusz

2006 Znaleziska monetarne z Ostrowa Tumskiego w Poznaniu, 119 k., tabl. (prom. Hanna Kóčka-Krenz, rec. Tadeusz Makiewicz, sygn. 19439)

\section{Siuda Marcin}

2004 Cmentarzysko z przełomu II i III okresu epoki brazu w Podrzeczu, powiat Gostyń, stan. 3, (prom. Aleksander Kosko, rec. Janusz Czebreszuk) 
153. Skarżyński Jakub

2003 Młodszy okres przedrzymski i okres wpływów rzymskich na terenie powiatu Środa Wielkopolska, 113 k., tabl. (prom. Tadeusz Makiewicz, rec. Hanna Kóčka-Krenz, sygn. 18488)

\section{Słonimska Marta}

2005 Kafle nowożytne z Zamku Bibersteinów (St. 1) i Pałacu Promnitzów (St. 2) w Żarach, 64 k., tabl. (prom. Danuta Minta-Tworzowska, rec. Hanna Kóčka-Krenz, sygn. 19114)

\section{Smug Łukasz}

2007 Problematyka zabaw i gier w średniowieczu w Wielkopolsce i na Śląsku w świetle źródeł archeologicznych - wybrane przykłady, (prom. Danuta Minta-Tworzowska, rec. Hanna Kóčka-Krenz)

\section{Sobolewska Natasza}

2006 Osada ludności grupy białowickiej w Lubieszowie, gm. Wymiarki, pow. Żagań, woj. lubuskie, 63 k., tabl. (prom. Jerzy Fogel, rec. Hanna Kóčka-Krenz, sygn. 19270)

\section{Sołtysiak Michał}

2004 Cechy miasta zachodniopomorskiego w średniowieczu w perspektywie badań archeologicznych, 175 k., tabl. (prom. Danuta Minta-Tworzowska, rec. Hanna Kóčka-Krenz, sygn. 18640)

\section{Sowiński Rafał}

2004 Etniczność jako przedmiot badań w archeologii - zarys problematyki, (prom. Danuta Minta-Tworzowska, rec. Aleksander Kośko)

\section{Sroka Bartosz}

2007 „Talatat” w budownictwie egipskim Nowego Państwa, 91 k., tabl. (prom. Rafał Koliński, rec. Dobrochna Jankowska, sygn. 19618)

\section{Stachowiak Paweł}

2006 Hutnictwo żelaza na Ziemi Lubuskiej w okresie wpływów rzymskich, 64 k., tabl. (prom. Tadeusz Makiewicz, rec. Hanna Kóčka-Krenz, sygn. 19271)

\section{Stempniak Sabina}

2006 Forum transitorium. Ideologia i fukcje architektonicznego kompleksu cesarskiego na tle zabudowy centrum antycznego Rzymu (prom. Leszek Mrozewicz, rec. Danuta Minta-Tworzowska)

\section{Stępień Rafał}

2004 Wczesnośredniowieczny skarb srebrny z Ostrowa nad Gopłem, 136 k., tabl. (prom. Jerzy Fogel, rec. Hanna Kóčka-Krenz, sygn. 18594)

163. Stryjewska Olga

2006 Wczesnośredniowieczny skarb monet z Gorzyc, 141 k., tabl. (prom. Danuta Minta-Tworzowska, rec. Hanna Kóčka-Krenz, sygn. 19272)

\section{Suchowska Paulina}

2005 Kontrowersje z chronologią. Wybuch wulkanu na Therze a stan debaty nad datowaniem początku późnego okresu epoki brązu w strefie egejskiej, 112 k., tabl. (prom. Janusz Czebreszuk, rec. Aleksander Kośko, sygn. 19852)

165. Sybal Mateusz

2005 Ofiary zakładzinowe w okresie średniowiecza na terenie Polski, 109 k., tabl. (prom. Hanna Kóčka-Krenz, rec. Danuta Minta-Tworzowska, sygn. 18999) 


\section{Szafrańska Violetta}

2007 Motywy architektoniczne na wielkopolskich kaflach piecowych z XV-XVIII w., 115 k., tabl. (prom. Jerzy Fogel, rec. Hanna Kóčka-Krenz, sygn. 19606)

167. Szlefarska Iwona (Frycz)

2003 Kafle i piece kaflowe z dworu w Chalinie, 180 k., tabl. (prom. Hanna Kóčka-Krenz, rec. Tadeusz Makiewicz, sygn. 18411)

168. Szturmowska Agnieszka

2005 Osada ludności kultury przeworskiej w Młodzikowie stan. 21, pow. Środa Wielkopolska, 59 k., tabl. (prom. Tadeusz Makiewicz, rec. Hanna Kóčka-Krenz, sygn. 19122)

\section{Szydłowski Marcin}

2003 Topogeneza grupy kościańskiej kultury unietyckiej, (prom. Aleksander Kośko, rec. Janusz Czebreszuk)

\section{Szymczak Michał}

2003 Przedmioty szklane i związane ze szklarstwem z grodziska wczesnośredniowiecznego w Lądzie, pow. Słupca, 81 k., tabl. (prom. Hanna Kòčka-Krenz, rec. Tadeusz Makiewicz, sygn. 19382)

171. Szymczak-Bagrowska Beata

2007 Wierzenia Słowian w świetle źródeł archeologicznych z ziem polskich, 73 k., tabl. (prom. Hanna Kóčka-Krenz, rec. Tadeusz Makiewicz, sygn. 19589)

\section{Szyszka Agnieszka}

2005 Ozdoby ze szkła, kamieni ozdobnych, bursztynu i gliny ze stanowiska Ostrów Tumski w Poznaniu, 132 k., tabl. (prom. Hanna Kóčka-Krenz, rec. Jerzy Fogel, sygn. 18988)

\section{3. Świejkowski Bartosz}

2007 Wczesnośredniowieczne osadnictwo okolic Jarocina, 162 k., tabl. (prom. Hanna Kóčka-Krenz, rec. Tadeusz Makiewicz, sygn. 19609)

\section{4. Świetlik Paweł}

2006 Wczesnośredniowieczne cmentarzysko w Gieczu. Analiza wyposażenia grobowego, 93 k., tabl. (prom. Hanna Kóčka-Krenz, rec. Jerzy Fogel, sygn. 19239)

\section{Tondos Karina}

2003 Mezolityczne narzędzia krzemienne ze stanowiska Żuławka 13, gm. Wyrzysk, pow. Piła, woj. Wielkopolskie, (prom. Dobrochna Jankowska, rec. Janusz Czebreszuk, sygn. 20361)

176. Vorbrich Kinga

2007 Świat dziecka i dziecko w świecie neolitycznej społeczności Ģatalhöyük (Turcja), (prom. Danuta Minta-Tworzowska, rec. Arkadiusz Marciniak)

\section{Walczak Piotr}

2003 Osadnictwo w pradziejach i wczesnym średniowieczu na ziemi świdnickiej, 89 k., tabl. (prom. Hanna Kóčka-Krenz, rec. Tadeusz Makiewicz, sygn. 18409)

178. Wawrusiewicz Adam

2006 Udział kultury pucharów lejkowatych w rozwoju społeczeństw strefy leśnej międzyrzecza Wisły i Dniepru. Perspektywa subneolitu kontynentalnego, (prom. Aleksander Kośko, rec. Janusz Czebreszuk)

179. Wenzel Julia

2006 Ceramika grafitowa z Ostrowa Tumskiego w Poznaniu, 92 k., tabl. (prom. Hanna Kóčka-Krenz, rec. Tadeusz Makiewicz, sygn. 19273) 
180. Wieromiej Katarzyna

2005 Wczesnośredniowieczny skarb z Murczyna, 97 k., tabl. (prom. Hanna Kóčka-Krenz, rec. Tadeusz Makiewicz, sygn. 19110)

181. Witczak Ewa

2007 Osady ludności kultury ceramiki wstęgowej rytej w Chełmiczkach, gm. Kruszwica, stanowisko 10 (pet 47), 162 k., tabl. (prom. Aleksander Kośko, rec. Janusz Czebreszuk, sygn. 19590)

\section{Włoka Aldona}

2005 Wykorzystanie muszli na terenie południowego Lewantu w okresie chalkolitu i we wczesnej epoce brązu I, (prom. Rafał Koliński, rec. Michał Kobusiewicz)

183. Wolff Paweł

2005 Kafle piecowe pozyskane podczas prac archeologicznych na rogu ulic Stawnej i Żydowskiej w Poznaniu, 123 k., tabl. (prom. Hanna Kóčka-Krenz, rec. brak, sygn. 18996)

184. Woltyńska Anna

2005 Kultura lateńska w Polsce południowej w świetle najnowszych badań, 74 k., tabl. (prom. Tadeusz Makiewicz, rec. Hanna Kóčka-Krenz, sygn. 19120)

\section{Wroczyńska Katarzyna}

2005 Szklane bransolety z Chersonesu, 74 k., tabl. (prom. Hanna Kóčka-Krenz, rec. Tadeusz Makiewicz, sygn. 18897)

186. Wróblewska Lidia

2006 Problem społecznego funkcjonowania archeologii we współczesnej Polsce, 119 k. (prom. Danuta Minta-Tworzowska, rec. Włodzimierz Rączkowski, sygn. 19381)

187. Wróblewski Oktawian

2006 Społeczności kultury amfor kulistych na Pałukach południowo-wschodnich, (prom. Aleksander Kośko, rec. Marzena Szmyt)

188. Wrzesiński Krzysztof

2003 Średniowieczne i nowożytne wyroby żelazne ze stanowiska Ostrów Tumski 9/10 w Poznaniu, 91 k., tabl. (prom. Hanna Kóčka-Krenz, rec. Jerzy Fogel, sygn. 18393)

189. Wujek Anna

2007 Analiza i interpretacja rytów naskalnych z terenów południowej Szwecji z epoki brązu, (prom. Danuta Minta-Tworzowska, rec. Aleksander Kośko)

190. Zamojski Ziemowit

2003 Wczesnośredniowieczna osada w Spławiu, stanowisko 1, gm. Kołaczkowo, pow. Września, woj. wielkopolskie, 59 k., tabl. (prom. Hanna Kóčka-Krenz, rec. Tadeusz Makiewicz, sygn. 18449)

191. Zawol Magdalena

2007 Biżuteria zachodniosłowiańska w skarbach skandynawskich, 186 k., tabl. (prom. Hanna Kóčka-Krenz, rec. Tadeusz Makiewicz, sygn. 19607)

\section{Ziomek Marcin}

2004 Znaczenie konia we wczesnym średniowieczu na terenie ziem polskich, 80 k., tabl. (prom. Hanna Kóčka-Krenz, rec. Tadeusz Makiewicz, sygn. 18658) 


\section{3. Żuchelkowski Paweł}

2004 Aspekty ekonomiczne tezauryzacji skarbów srebrnych o charakterze monetarnym w okresie wczesnego średniowiecza w Polsce ze szczególnym uwzględnieniem terytorium Wielkopolski, 133 k., tabl. (prom. Hanna Kóčka-Krenz, rec. Tadeusz Makiewicz, sygn. 18892)

\section{4. Żukowska Małgorzata}

2006 Miasta transjordańskiego Dekapolis. Studium urbanistyczne okresu hellenistyczno-rzymskiego, (prom. Rafał Koliński, rec. Leszek Mrozewicz)

\section{5. Żybura Izabela}

2003 Osadnictwo wczesnośredniowieczne na Ziemi Leszczyńskiej, 88 k., tabl. (prom. Danuta Minta-Tworzowska, rec. Hanna Kóčka-Krenz, sygn. 18348)

\section{PRACE DOKTORSKIE}

\section{Klenina Elena}

2005 Stołowa i kuchenna ceramika III-IV wiek z Novae (Północna Bułgaria), (prom. Tadeusz Makiewicz, rec. Aleksander Ajbabin, Piotr Dyczek, Grzegorz Domański)

\section{Krajewski Przemysław}

2003 Analiza przestrzenna osadnictwa wyspy Wolin i prawego brzegu Dziwny od środkowego okresu epoki brązu do wczesnej epoki żelaza. (prom. Danuta Minta-Tworzowska, rec. Włodzimierz Rączkowski, Sławomir Kadrow)

\section{Mączyńska Agnieszka}

2003 Społeczności Delty Nilu w okresie predynastycznym (3800-3300/3200 BC) oraz ich kontakty z Palestyną, (prom. Lech Krzyżaniak, Dobrochna Jankowska, rec. Michał Kobusiewicz, Krzysztof Ciałowicz)

199. Pawleta Michał

2005 Koncepcje dziecka i dzieciństwa w perspektywie badań archeologicznych neolitu środkowoeuropejskiego, (prom. Danuta Minta-Tworzowska, rec. Włodzimierz Rączkowski, Jacek Woźny)

\section{Pietrzak Sławomir}

2006 Zastosowanie i technologie wytwarzania dziegciu wśród społeczeństw międzyrzecza Dniepru i Łaby od VI do II tysiąclecia BC., (prom. Jerzy J. Langer, rec. Lech Czerniak, Aleksander Kośko)

\section{Przybył Agnieszka}

2007 Badenizacja niżowych ugrupowań kultury pucharów lejkowatych w międzyrzeczu Odry i Wisły: 3600/3500-2400/2350 przed Chrystusem. Podstawy systematyki chronologiczno-przestrzennej, (prom. Aleksander Kośko, rec. Janusz Kruk, Marzena Szmyt)

\section{Rola Jarosław}

2003 Późnoneolityczny węzeł komunikacyjny w strefie środkowej Noteci (Żuławka Mała, gmina Wyrzysk), (prom. Aleksander Kośko, rec. Lucyna Domańska, Marzena Szmyt) 
203. Różański Artur

2005 Jednoprzestrzenne kościoły romańskie z terenu Wielkopolski, (prom. Hanna Kóčka-Krenz, rec. Jadwiga Chudziakowa, Józef Dobosz)

204. Skowron Justyn

2004 Kultura przeworska w rejonie środkowej i dolnej Bzury. Studium z dziejów osadnictwa, (prom. Tadeusz Makiewicz, rec. Stanisław Pazda, Hanna Kóčka-Krenz)

205. Ślusarska-Michalik Katarzyna

2004 Systemy wierzeniowo-obrzędowe północnego Nadczarnomorza w trzecim i początku drugiego tysiąclecia przed Chr., (prom. Aleksander Kośko, rec. Lech Czerniak, Janusz Czebreszuk)

206. Wojnicz Joanna

2007 Zamek i klasztor Oybin: studium archeologiczne. T. 1-2, (prom. Hanna Kóčka-Krenz, rec. Jadwiga Chudziakowa, Jerzy Piekalski)

207. Zapłata Rafał

2005 Archeologiczne studia na przestrzenią : zastosowanie Systemów Informacji Geograficznej w badaniach nad wczesnośredniowiecznym osadnictwem grodowym na Pomorzu. (prom. Danuta Minta-Tworzowska, rec. Jacek Woźny, Włodzimierz Rączkowski)

208. Żychliński Daniel

2003 Obrządek pogrzebowy w Wielkopolsce w okresie od młodszego okresu przedrzymskiego do okresu wędrówek ludów : (od schyłku III w. p.n.e. do początków VI w. n.e.), (prom. Tadeusz Makiewicz, rec. Grzegorz Domański, Magdalena Mączyńska)

\section{PRACE HABILITACYJNE}

209. Pelisiak Andrzej

2003 Osadnictwo, gospodarka, społeczeństwo. Studia nad kulturą pucharów lejkowatych na Niżu Polskim (rec. Dobrochna Jankowska, Janusz Kruk, Jan Machnik)

\section{Marciniak Arkadiusz}

2006 Placing Animals In the Neolithic Social zoomorarchaeology of prehistoric forming communities (rec. Alicja Lasota-Moskalewska, Danuta Minta-Tworzowska, Janusz Kruk, Norbert Jan Pospieszny)

\section{SKOROWIDZ CHRONOLOGICZNY}

Paleolit 23, 28, 40, 68, 77, 142, 150

Mezolit 132, 175

Neolit 11, 18, 60, 97, 100, 123, 128, 139, 178, 181, 187

Epoka brązu 4, 5, 16, 20, 21, 34, 39, 53, 54, 59, 74, 80, 90, 93, 113, 152, 169, 189

Okres halsztacki 5, 93, 94, 110, 120

Okres przedrzymski 17, 69, 95, 109, 131, 184

Okres wpływów rzymskich $3,36,45,55,57,62,71,79,88,107,125,126,127,153,156,160$, 168 
Okres wczesnośredniowieczny 2, 7, 8, 10, 15, 24, 27, 33, 35, 41, 43, 48, 49, 51, 52, 58, 61, 63, 64, $73,78,83,84,87,92,99,105,108,114,118,133,134,140,144,145,146,148,151,162$, $163,170,171,172,173,174,180,190,191,192,193,195$

Średniowiecze i okres nowożytny 1, 6, 12, 14, 22, 31, 37, 44, 66, 72, 81, 98, 103, 115, 119, 121, $138,149,154,155,157,165,166,167,179,183,188$

Historia, teoria i metodologia archeologii $29,38,46,67,70,76,89,96,104,112,130,136,147$, 158,186

Archeologia orientalna i antyczna $13,19,25,26,30,32,42,47,50,56,65,75,82,85,86,91,101$, $102,106,111,116,117,122,124,129,135,141,143,159,161,164,176,182,185,194$

Opracowała Jolanta Walkiewicz Biblioteka Instytutu Prahistorii UAM, Uniwersytet im. Adama Mickiewicza ul. Św. Marcin 78, 61-809 Poznań, Poland 